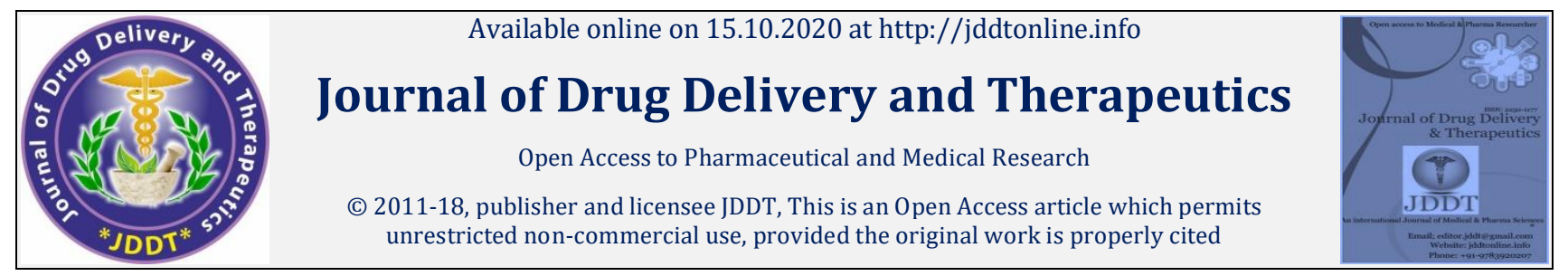

Open 1 Access

Case Report

\title{
Co-Trimoxazole Induced Severe Cutaneous Adverse Reaction: A Challenging Diagnosis
}

\author{
Sreehari M 1, Sana M M 1*, Tom Cyril ${ }^{2}$ \\ 1 Pharm D Intern, Shree Devi College of Pharmacy, Mangaluru, Karnataka, India \\ ${ }^{2}$ Assistant Professor, Department of Pharmacy Practice, Shree Devi College of Pharmacy, Mangaluru, Karnataka, India
}

\begin{abstract}
Introduction; Drug Reaction with Eosinophilia and systemic symptoms (DRESS) Syndrome is a life-threatening reaction with a mortality rate of $10-20 \%$. Usual reaction period is 2 to 6 week after the first intake of drug. The present case is an example of late presentation of the symptoms which made the diagnosis difficult.

Clinical case: We describe a case of 51 year old male with known history of Acquired ImmunoDeficiency Syndrome (AIDS) and Tuberculosis (TB) presented with complaints of fever, generalised scaling, oedema, eosinophilia and elevated liver enzymes. The symptoms started 45 days back but was then misdiagnosed and treated as exfoliative dermatitis from a local hospital. The symptoms aggravated since 5 days and were admitted in our hospital. Drug reaction was least suspected as he has been taking the Antiretroviral (ART) and Anti-tubercular (ATT) drugs since 3 to 4 months. But later on culprit drug was identified to be Sulfamethoxazole-Trimethoprim and was soon discontinued. Significant improvement was seen with steroid, antihistamines and other topical agents.
\end{abstract}

Discussion: Timely recognition of DRESS Syndrome, prompt discontinuation of culprit drug and symptomatic management are imperative in a better prognosis. It must also be noted that the latency period can be as long as 105 days after the first intake of the drug, rather than the usual presentation period of 2-6 week.

Article Info: Received 07 Aug 2020; $\quad$ Review Completed 13 Sep 2020; $\quad$ Accepted 19 Sep 2020; Available online 15 Oct 2020

Cite this article as:

Sreehari M, Sana MM, Tom C, Co-Trimoxazole Induced Severe Cutaneous Adverse Reaction: A Challenging Diagnosis, Journal of Drug Delivery and Therapeutics. 2020; 10(5-s):191-194 http://dx.doi.org/10.22270/jddt.v10i5-s.4428

*Address for Correspondence:

Sana M M, Shree Devi College of Pharmacy, Mangaluru, Karnataka, India. Pin: 575003

\section{INTRODUCTION}

Drug Reaction with Eosinophilia and systemic symptoms (DRESS) Syndrome is a rare 1, life-threatening 2, hypersensitivity reaction with a mortality rate of $10-20 \%{ }^{3}$. Clinical handling of adverse drug reaction (ADR) is difficult, especially in HIV as some ADRs gets potentiated with it 4. Stringency and Frequency of ADRs increase exponentially with the disease progression 5 .

Trimethoprim-Sulfamethoxazole (TMP-SMX) is accountable for $40-80 \%$ ADR in HIV patients compared to $3-5 \%$ in the general population 6 . Anti-tubercular drugs are also well known instigators of the syndrome. Still, the lack of a gold standard for its diagnosis makes it difficult and clinical judgement is paramount 6 . The reaction shares clinical characteristics with other dermatologic conditions, mandating the physicians to closely investigate to attain a rightful diagnosis 7 . It is still challenging to identify the culprit drug among the pool.

We present a case of late presentation and diagnosis of TMPSMX induced DRESS in an HIV patient.

\section{CASE PRESENTATION}

A 51-year-old male patient with a BMI of $14.33 \mathrm{~kg} / \mathrm{m}^{2}$ and with a known history of Acquired Immunodeficiency Syndrome (AIDS) and Tuberculosis (TB) visited the hospital on $11^{\text {th }}$ February 2020 with complaints of generalised scaling and redness, which aggravated since 5 days. The reaction was started 45 days back in mild grade and was prescribed with liquid paraffin suspecting it as HIV associated exfoliative dermatitis from a local hospital. He also underwent some traditional treatment.

On initial examination, the patient was found febrile $\left(99.1^{\circ} \mathrm{F}\right)$ and hypotensive $(100 / 60 \mathrm{mmHg})$ with severe erythematous, itchy and diffuse scaling presenting all over the body except soles and palms (Figure 1). He also had mild facial and pedal oedema. He furthermore complained of red and watery eyes.

Laboratory investigation reveals an elevated eosinophil count (26\%), ESR $(48 \mathrm{~mm} / \mathrm{hr}$ ) and liver enzymes (SGPT - 65 U/L, ALP-164 U/L). Chest X-ray showed bilateral opacities predominantly in the left lower zone. Dermatologist ruled out other skin disorders including Psoriasis and he agreed with the physician's suspicion of a drug reaction. 
In view of patient's symptoms, hepatic involvement, clinician's judgement and a "Possible" score in RegiSCAR
(Table 1), DRESS syndrome was confirmed.
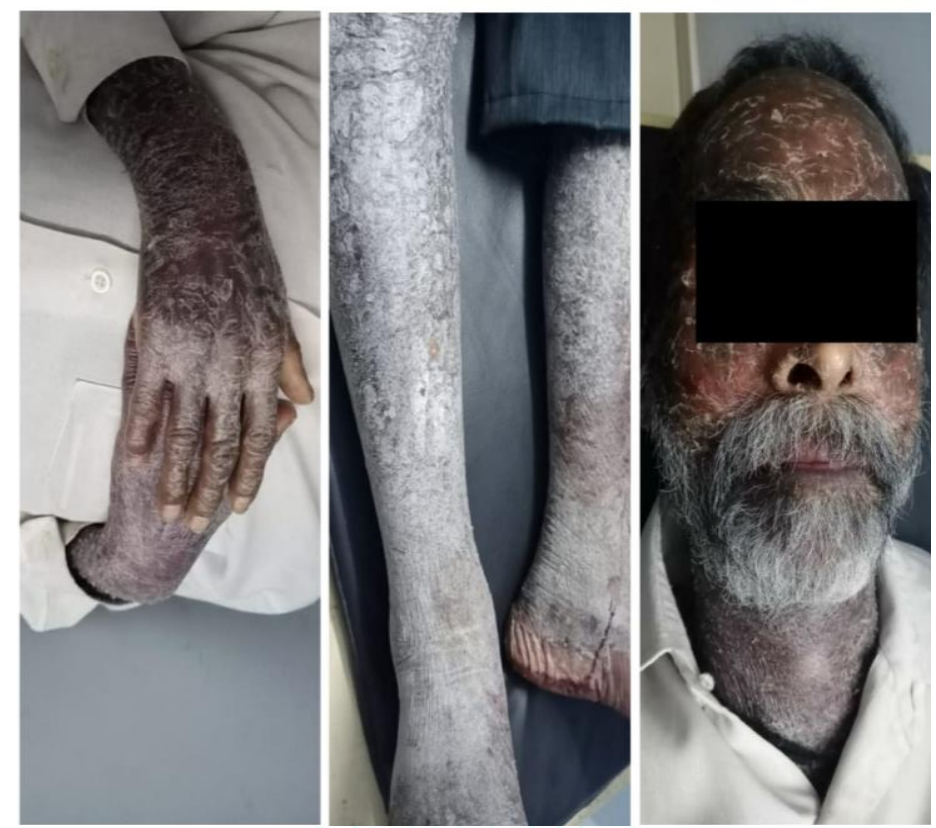

Figure 1: Patient on Day 1

Table 1: RegiSCAR Score

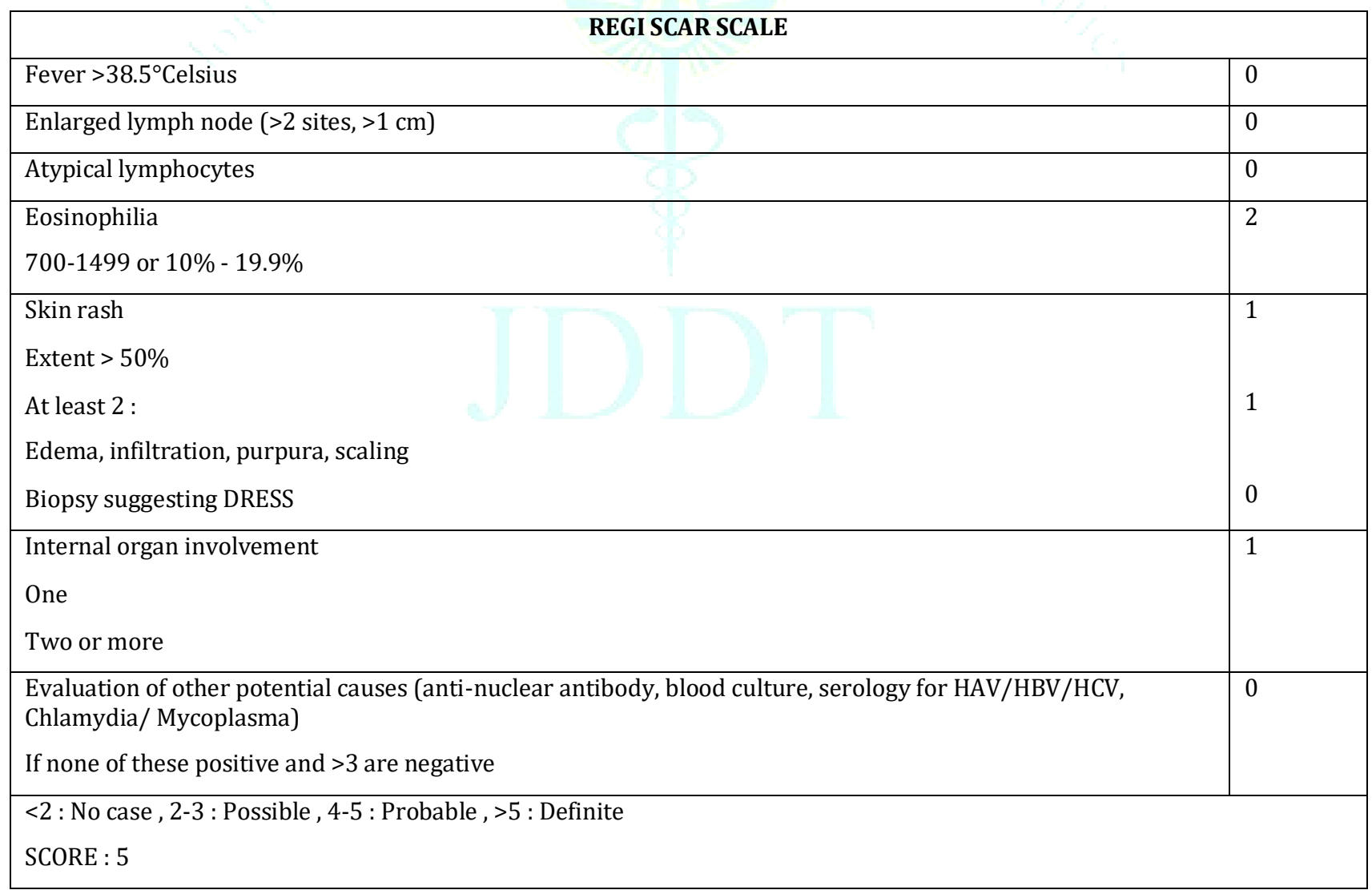

With a personal interview, patient's medication history was found to be as follows:

ATT (Continuation phase) - Isoniazid, Rifampicin, ethambutol- started on 21st September 2019.

ART - Tenofovir, Lamivudine, and Efavirenz- started on 22nd October 2019. And

Antibiotic- Trimethoprim-Sulfamethoxazole (TMP-SMX) - started on 22nd October 2019. 
All the drugs except ART was withdrawn on the Day of admission and symptomatic treatment was given with Steroids, Antihistamines and nutritional supplements.

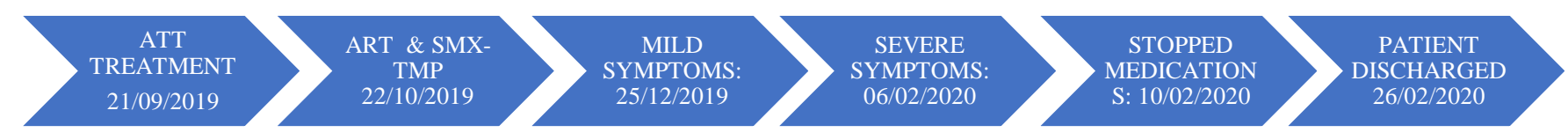

Figure 2: Drug Administration Timeline

On day 7, Isoniazid 450mg OD and Ethambutol 800mg OD were rechallenged uneventfully. Rifampicin 300mg OD was reintroduced on Day 10 , and on absense of symptoms it was titrated to $600 \mathrm{mg}$ OD on Day 13. Patient tolerated well and was symptomatically improved. Meanwhile steroid tapering was initiated (Table 2). Co-trimoxazole was not rechallenged as the physician suspected it and rifampicin the most. On assessing causality using Naranjo Scale; association was found Probable for Co-trimoxazole.

He got discharged on Day 16 with prednisolone, antihistamines and other topical agents.

Table 2: Steroids Prescribed.

\begin{tabular}{|l|l|l|l|l|}
\hline Sl No & Steroid & Dose & Route & Date \\
\hline 1 & Inj Dexamethasone & $8 \mathrm{mg}-0-4 \mathrm{mg}$ & IV & Day $0,1,2$ \\
\hline 2 & Inj Dexamethasone & $8 \mathrm{mg}-0-0$ & IV & Day $3,4,5$ \\
\hline 3 & Inj Dexamethasone & $4.5 \mathrm{mg}-0-0$ & IV & Day $6,7,8$ \\
\hline 4 & Tab Prednisolone & $30 \mathrm{mg}-0-0$ & PO & Day $9,10,11$ \\
\hline 5 & Tab Prednisolone & $20 \mathrm{mg}-0-0$ & PO & Day $12,13,14$ \\
\hline 6 & Tab Prednisolone & $10 \mathrm{mg}-0-0$ & PO & Day $15,16,17$ \\
\hline
\end{tabular}
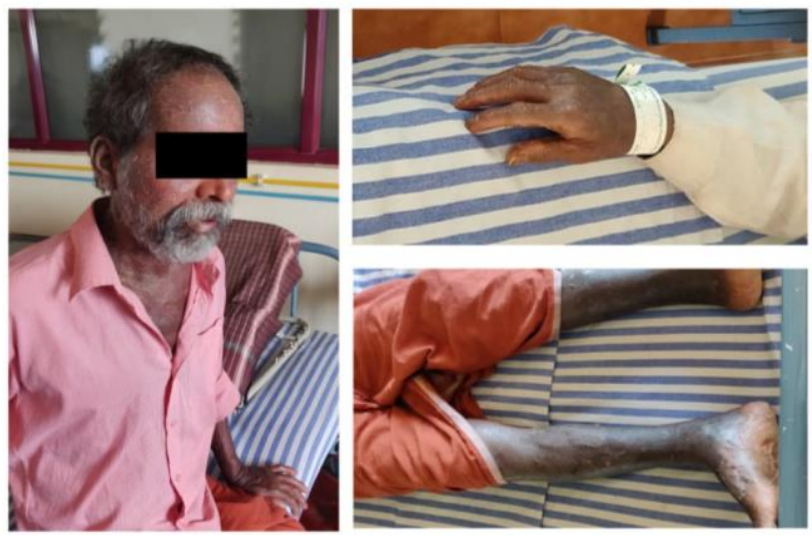

Figure 3: On Day 6 - Patient Recovering

\section{DISCUSSION}

DRESS Syndrome is a severe Type IV (Delayed type) hypersensitivity reaction commonly seen in HIV patients. But multiple co-morbidities and co-infections make it challenging for prompt diagnosis and cessation of the culprit drug. In our case, the patient had a mild cutaneous reaction for about 1 and half months but was misdiagnosed with HIV associated exfoliative dermatitis. Due to the non-specific clinical features, DRESS syndrome mimics many other conditions considerably affecting the prognosis. The signs of fever, skin and organ involvement in DRESS, often led to speculate infectious disease as the primary diagnosis 8 . The suspicion to DRESS curtails after the usual reaction period of 2-6 week as discerned in our case. But it must be duly noted that the latency period can be as long as 105 days after the first intake of drug 9 .

RegiSCAR is primarily used to attain the diagnosis of DRESS. According to RegiSCAR scoring system, features of DRESS include fever, eosinophilia, lymphadenopathy, atypical lymphocytes, skin rash, visceral organ involvement, and duration of disease more than fifteen days. But it was observed that, patients defined as "no/possible cases" by the scoring system accounted for almost one-quarter of all the reported DRESS cases ${ }^{10}$. This can lead to misdiagnosis, thereby increasing morbidity and mortality.

An important concern to work out was to identify the source of reaction from the multiple drugs. Hence all the suspected drugs were withdrawn and the least suspected and most essential ones for the patient were restarted at a lower dose with caution. A decision not to rechallenge TMP-SMX was taken in our case, as it wasn't essential and to avoid severe consequences as our team highly suspected it as the cause. Even though steroid treatment in DRESS results in a substantial improvement, consensus are lacking regarding the choice, dose and duration of steroids. Further researches are necessary to propose specific diagnostic and treatment protocols for the syndrome.

\section{CONCLUSION:}

Although drug reaction is common in HIV, due to clinical similarities with other skin conditions it is often misdiagnosed. We present this case so that the DRESS syndrome should be considered in patients with a cutaneous reaction among other differential diagnoses even after the 
usual presentation period of 2 to 6 weeks. The latency period of DRESS can be as long as 105 days. A rightful diagnosis of DRESS requires a physician with high degree of suspicion to exclude the mimickers.

\section{Sources of Support: Nil}

\section{Conflicting Interest: Nil}

\section{REFERENCES}

(1) Wolfson AR, Zhou L, Li Y, Phadke NA, Chow OA, Blumenthal KG. Drug Reaction with Eosinophilia and Systemic Symptoms (DRESS) Syndrome Identified in the Electronic Health Record Allergy Module. JACI. 2019; 7(2):633-640.

(2) Abhishek De, Rajagopalan M, Aarti Sarda A, Das S, Biswas P. Drug reaction with eosinophilia and systemic symptoms: An update and review of recent literature. IJD.2018; 63(1):30-40.

(3) Waseem D, Latief M, Sofi N, Dar I, Khan Q, Abbas F, Sofi P. Dress Syndrome: A review and update. Skin Dis Skin Care. 2016; 1:1.

(4)Arp J, Rieder MJ, Urquhart B, Freeman D, Tucker MJ, Krizova, et al. Hypersensitivity of HIV-1-infected cells to reactive sulfonamide metabolites correlated to the expression of the HIV-1 viral protein Tat. JPET. 2005; 314(3):1218-1225.
(5) Meyer C, Behm N, Brown E, Copeland NK, Sklar MJ. An Adverse Drug Reaction to Trimethoprim-Sulfamethoxazole Revealing Primary HIV: A Case Report and Literature Review. Case Reports in Infectious Disease. 2015; 2015:691010.

(6) Coopman SA, Stern RS. Cutaneous drug reactions in human immunodeficiency virus infection. Arch Dermatol. 1991; 127(5):714-717.

(7) Husain Z, Reddy BY, Schwartz RA. DRESS syndrome: Part II. Management and therapeutics. JAAD. 2013; 68(5):709.

8) Lee HY, Walsh S, Creamer D. Initial Presentation of DRESS: Often Misdiagnosed as Infections. Arch Dermatol. 2012; 148(9):10851087.

9) Um SJ, Lee SK, Kim YH, Kim KH, Son CH, Roh MS, et al. Clinical features of drug-induced hypersensitivity syndrome in 38 patients. JIACI.2010; 20(7):556-562.

10) Cacoub P, Musette P, Descamps V, Meyer O, Speirs C, Finzi L, et al. The DRESS Syndrome: A Literature Review. AMJ. 2011; 124(7):588-597

11) Choudhary S, McLeod M, Torchia D, Romanelli P.Drug Reaction with Eosinophilia and Systemic Symptoms (DRESS) Syndrome. JCAD. 2013; 6(6):31-37. 